\title{
Meetings as Persistent Conversations that use ICTs and Face-to-Face to Build Social Capital
}

\author{
Keri K. Stephens \\ The University of Texas at Austin \\ keristephens@,austin.utexas.edu \\ Eric D. Waters \\ Marquette University \\ eric.waters@marquette.edu
}

\author{
Ignacio Cruz \\ University of Southern California \\ ignacioc@usc.edu \\ Yaguang Zhu \\ The University of Texas at Austin \\ yaguang.zhu@utexas.edu
}

\begin{abstract}
Attending meetings is a common activity where people accomplish tasks and extend their relationships. But what happens when a meeting is over? Is that the end of the meeting conversation? This study empirically demonstrates that meetings are not discrete events; rather they are a form of persistent conversation processes, involving combinations of ICTs and face-toface communication. Conversations between meetings contribute to a meeting process-perspective and link to the development of bonding and bridging social capital. The findings suggest that the frequency of face-to-face conversations and text messaging between meetings, positively impact bonding social capital. Peoples' attitudes toward continuing conversations between meetings positively impacts bridging social capital. The frequency of using many contemporary ICTs-e.g., Facebook, Twitter, and GroupMe-between meetings was not a significant predictor in developing social capital, even in a sample of young adults.
\end{abstract}

\section{Introduction}

Meetings are a central place where people communicate at work and in their personal lives [1-3]. Voluntary membership organizations, in particular, are different from work organizations because people join these groups to meet their leisure, interest, and friendship needs [4-6]. In these types of organizations, people from disparate locations convene at specific times and the conversational thread is woven around specified meetings. These interactions not only allow groups to accomplish tasks, but they also help people form relationships that can benefit them socially, economically, and personally [4,7].

Now that people have access to information and communication technologies (ICTs) around the clock, meetings have changed in many ways $[9,10]$. ICTs free meeting conversations from the lock-step synchrony of face-to-face conversation [11] and render people accessible in different places and at later times [12]. Processes of turn-taking and topic maintenance through ICTs build up interactional coherence that facilitate persistent meeting conversations $[13,14]$. For example, emails are used to deliver agendas before meetings, and after meetings, emails are sent to follow-up [15]. Instant messages are leveraged to arrange and coordinate scheduled and impromptu meetings through conversational coherence in virtual teams [14]. Increasingly, people are using meeting tools and social networking sites (SNS) to collaborate and determine ideal meeting times [15], contribute agenda items, and create meeting invites on Facebook [16]. Yet we know very little about how people communicate between meetings and the impact their interactions have on subsequent face-to-face (FtF) meetings.

Researchers who have considered between-meeting activities tend to focus on meeting follow-ups or premeeting conversations $[15,17,18]$. While this research has helped expand the idea of meeting boundaries, these concepts still compartmentalize meetings based on a pre-meeting, during meeting, and post-meeting framework. This current study shifts the conceptualization of a meeting to that of a process, instead of a discrete event. We empirically demonstrate how between-meeting conversations work with combinations of ICTs and FtF meeting conversations to constitute a meeting process. This approach responds to calls for more conceptual work on meetings [19] and for requests to analyze existing ICT-mediated conversational practices that constitute and perpetuate organizational lives $[11,12]$.

We test our research models using a crossorganizational sample of young adults from over 230 different voluntary membership organizations. To accomplish our research goals, first we develop a conceptual model that combines variables known to influence meeting behavior with an added set of 
variables focused on between-meeting communication. Next, we discuss the relevance of social capital as a keymeeting outcome that is linked to relationship building. We rely on conceptualizations of bonding and bridging forms of social capital [4,8,20]. Finally, we share the implications of the research and provide specific applications useful for extending this work to other contexts and outcomes.

\section{Meetings as process, not isolated events}

Schwartzman (1989) defined meetings as communicative events that include three or more people and address issues of concern to the group or a larger community. Today, technology is playing an increasing role in extending meeting boundaries. Theoretical work on ICT use, including FtF, proposes how combinatorial ICTs might be used between meetings (ICT Succession Theory, [21]). Empirical studies have found that people use a mix of ICTs to search for information and communicate with others before they attend a meeting, and they also follow up using ICTs after a FtF meeting [18]. In Chudoba et al.'s study of distributed meetings [15], one respondent explained: "Email is distributed mainly after meetings - we may share ideas between meetings. The electronic discussion may reach a level that the item will be added to next week's meeting" ( $\mathrm{p}$. 17). This quote explains that cycle; conversations occurring after a discrete meeting, become the premeeting items for the next discrete meeting: a form of persistent conversation.

This prior work, combined with the growth in ICT use, and the documented knowledge that groups change over time [22], leads us to argue that since ongoing conversations occur between meetings, we should conceptualize meetings as a process. We still acknowledge that discrete meeting events occur and constitute what people call "a meeting," but we need to more fully consider what happens around meetings as part of an integrated process.

\subsection{Variables influencing discrete meetings}

For us to argue that meetings are a process, it is important to explore how the process perspective contributes to the current understanding of what happens during a discrete meeting. Therefore, we first examine in-meeting variables that can affect meeting experiences and relationship development.

Past research has shown that individual-level variables affect how people perceive a meeting and include the role the person has in the meeting $[23,24]$ and their tenure in the organization [24, 25]. Meeting load is also an important predictor of meeting satisfaction [26]. Since people often join voluntary membership organizations to meet their leisure and interest needs [4], people attending many meetings will likely have a different perception of information load than individuals attending few meetings [26], so we include this variable in our model. Together, these variables serve as conceptual measures of individual engagement; something that should affect relationships and thus social capital.

Meeting-related variables, like the size of the meeting, also have been shown to influence meeting outcomes like perceived effectiveness [27]. Finally, scholars studying meetings and teams have found that the attitude people have toward their meetings can affect a variety of outcomes like satisfaction [23], inclusion and belonging [28], and relationship development [3]; variables related to social capital development.

\subsection{Using combinatorial ICTs to continue meeting conversations}

A process perspective on meetings suggests that if we only study what happens during a discrete meeting, we miss important opportunities to examine how relationships are built and how tasks are accomplished through between-meeting conversations. Prior research has identified two main reasons to have conversations between meetings: relationship development and coordination [15]. Furthermore, many of these betweenmeeting conversations happen through combinations of ICTs. Coordination purposes include activities like doing meeting pre-work over email before attending a FtF meeting [18]. Relationship development also occurs by continuing conversations through ICTs since combinations of $\mathrm{FtF}$ and technologies are often needed to strengthen relationships [15].

There are many ICTs that can be used to connect meeting attendees. Now that many people own personal communication devices-e.g., mobile phones with text messaging, email, and social networking sites - access can be more frequent [29]. This new personal communication society allows people to connect interpersonally and develop interpersonal bonds [30]. These connections are very important in voluntary membership organizations [4].

More recently, social media also have changed relationship building and social information seeking in ways informative for a meeting process perspective. When studying college students' use of Facebook, there is evidence that when people engage in social information seeking, they increase their bonding social capital [30]. There is also evidence that SNS play an important role in developing bridging social capital [3134]. Likewise, in workplace settings researchers found enterprise social media can facilitate the development of personal relationships and work-related collaborations in the offline world [35]. Consequently individuals may be able to increase their social capital by expanding their 
networks or bridging across structural holes based on a persistent textual record of the conversations and contacts on enterprise social media [12].

\section{Social capital as a key meeting outcome}

Social capital can be defined as the resources that develop and are accumulated from the relationships that people form with others [7]. Here we focus on individual social capital, based on the relationships and connections that members form with others in the organization. Individuals may develop social capital through resources that they attain from other individuals in their networks, including access to information [7,20] and the formation of personal relationships [8].

In this study, we conceptualize and operationalize social capital using two different forms: bonding and bridging. Bonding social capital refers to the benefits and support individuals receive from their close, inner circle of contacts, including family and friends [8]. Through a meeting lens, bonding social capital refers to the familiar intimate relationships formed with other members in the organization that can provide emotional support through interactions. The second form of social capital, bridging, refers to the type of resources and benefits that individuals experience based on their "weak or latent ties," such as acquaintances. The concept of weak ties originated with Granovetter [26] and his subsequent work that demonstrated how people, more loosely connected, share less redundant and more beneficial information. Thus, bridging social capital enables individuals to gain new, diverse perspectives from ties that do not form as part of their usual, inner circle of contacts [8].

\section{Research questions and hypotheses}

We argue that an important outcome of participating in voluntary membership meetings stems from the ability to develop bonding and bridging social capital. Interactions between members can cultivate relationships that can be identified as (a) strong tiesdefined as close, supportive, and trusting relationships [7] - that lead to bonding social capital, and (b) weak ties - more distant relationships [26] - that lead to bridging social capital [8].

Our first hypothesis and research question focus on discrete meetings and include the variables past research have shown to influence relationship development. These variables are most closely linked to bonding social capital because they are primarily strong tie relationship development; thus, we pose a hypothesis for discrete meeting effects on bonding social capital. However, it is quite possible that these meeting variables are also related to bridging social capital. Weak ties may be affected by discrete meeting factors and therefore, we ask a research question for bridging social capital.

H1: During FtF meetings, meeting role, membership tenure, meeting size, total organizational membership, perceived overload, and attitude toward the $\mathrm{FtF}$ meeting will influence the development of bonding social capital.

RQ1: During FtF meetings, to what extent do meeting role, membership tenure, meeting size, total organizational membership, perceived overload, and attitude toward the $\mathrm{FtF}$ meeting describe the development of bridging social capital?

\subsection{Continuing conversations between meetings through ICTs and FtF conversations}

To demonstrate the unique contribution of a process theory perspective on meetings, we need to show that moving beyond a discrete event has an impact on outcomes, specifically social capital in this study. While we acknowledge that in some voluntary organizations, FtF meetings are subordinate to these more informal conversations, to develop our process perspective, it is important to show the unique contribution of these continued conversations. Therefore, we specify how these conversations are continued and the core variables that influence these between-meeting conversations. Since we know that technology-use increasingly plays a salient role in the meeting process, it follows that the frequency with which people use ICTs along with FtF communication should have an impact on social capital development. Because we include ICTs in our model, we will also include expertise with using those ICTs. Finally, past research on ICTs like Facebook suggests that the attitudes young adults have when using relationship management tools can affect their use of those ICTs [32]. Since our model suggests that ICTs will be used to continue conversations, we will include a measure of people's attitude toward continuing conversations and it will be comparable to the attitude measure of FtF meetings.

Taken together, these between-meeting variables should contribute significantly to social capital development, above and beyond what discrete meeting predictors contribute. This leads to the following hypothesis:

$\mathrm{H} 2$ : Between FtF meetings, the more frequently

people use ICTs and have FtF conversations, along with their technology expertise and their attitude toward continuing conversations between meetings, will contribute significantly to the development of bonding and bridging social capital.

We can predict that ICTs allow people to connect and continue to build strong and weak ties between meetings, but predicting effects of specific ICTs is more 
difficult. There is growing research that links SNSspecifically Facebook - to the development of bridging social capital in college students $[31,32,34,36]$ and working adults [33]. We also know that text messaging is used to foster personal relationships [29] and email is a dominant ICT in work organizations for sending meeting agendas and following up after meetings $[15,18]$. But that research has not linked those ICT use behaviors to specific forms of social capital and they have not been studied in volunteer-membership organizations. Furthermore, there are new video and internet-based meeting technologies that have not been explored in the meeting conversation context. Therefore, we ask the following research question:

RQ2: When used to continue meeting conversations, how does the frequency of using specific ICTs and FtF conversation describe the development of bonding and bridging social capital?

\section{Method}

\subsection{Participants and procedures}

Participants were recruited from a large U.S. university in the Southwestern area of the United States and a key criterion for participation was involvement in at least one student organization on campus where membership was voluntary. These participants were recruited from a multi-major subject recruitment pool, accessed an online survey, and were awarded extra credit for their participation. Most participants reported attending one to two meetings a week $(N=223)$ with 53 attending three or more meetings a week. All participants selected one organization where they regularly attend meetings and answered the questions based on this single organization. Since this study examined communication practices that occurred between FtF meetings, participants indicating they rarely met $\operatorname{FtF}(N=13)$ were removed from the sample.

The resulting sample $(N=279)$ was $21.3 \%(N=59)$ male and $78.7 \%(N=218)$ female and had an average age of $M=20.33, S D=1.36$. Participants represented a wide range of student organizations $(N=230)$, including student government, major-specific groups, Greek, service organizations, and sports groups. These organizations varied in size and $63.1 \%(N=176)$ participants chose to report data from an organization with more than 50 members. Meeting size varied and 166 participants attended meetings with 50 or more attendees, while 124 participants attended smaller meetings with less than 50 attendees. The majority of the subjects had membership tenure in that organization for over one year $(N=175,62.9 \%)$.

\subsection{Discrete meeting predictors}

To assess the impact of discrete meeting predictors on social capital development, we measured the following predictors. Unless otherwise indicated, variables were assessed on a Likert-type scale ranging from strongly disagree (1) to strongly agree (7).

5.2.1. Membership level. Subjects were asked to indicate whether their role in the organization was a leader or member. Leaders were defined as those participants who identified their role as an executive officer or a leader of a specific committee $(N=84$, $30.7 \%)$. The remaining sample $(N=190,69.3 \%)$ were considered members without a specific leadership role. This variable had an $M=1.31, S D=.46$.

5.2.2. Membership tenure. This was assessed by asking length of membership. This variable was dichotomized into less than a year and a year or more because these students rarely have over a four-year tenure. It had a resulting $M=1.64, S D=.48$.

5.2.3. Meeting size. Participants were asked how many people attended the average organizational meeting. This variable was dichotomized: under 50 and 50 and over. It had an $M=1.36, S D=.48$.

5.2.4. Total organizational membership. We asked participants how many organizations they were a member of and this had an $M=1.19, S D=.39$.

5.2.5. Perceived overload. General, not ICT-specific overload, was measured using three items. These items have been used as part of a four-item scale in several studies $[8,38]$. The removed item was not relevant here because it combined phone calls and meetings into a single measurement item. A principal components factor analysis with varimax rotation revealed a single factor for this three-item scale and created a composite variable with $\alpha=.90, M=4.04$, and $S D=1.71$.

5.2.6. Attitude toward FtF meetings. We used a sixitem measure, anchored by never and always, to assess meeting attitudes [38]. We modified the stem to address the context of this study and it read, "These meetings are." A principal components factor analysis with varimax rotation confirmed a single factor and these items resulted in an $\alpha=.92, M=5.69$, and $S D=1.13$.

\subsection{Between meeting predictors}

5.3.1. Perceived ICT-use expertise. We added two items to an existing scale [8]. These items were measured on a scale ranging from novice (1) to expert (7). A principal components factor analysis with varimax rotation revealed a single factor for this three- 
item scale and created a composite measure with $\alpha=.85$, $M=6.14$, and $S D=0.88$.

\subsubsection{Frequency of using specific ICTs to continue} conversations between meetings. These individual ICT measurement predictors were created for this study and used the anchors of never and always. The stem appearing before these ICT options said: "After having a typical meeting, how often do you continue discussing meeting content in between meetings through:" To determine the ICTs used on this campus, our research team conducted 22 interviews with students and asked them to list all the ICTs they use to communicate with others in their organizations. These interviews produced the following $11 \mathrm{ICT}$ s plus FtF conversation included in the study: text messaging, Facebook, Instagram, Twitter, Vine, Skype, Video chat, Google Hangout, GroupMe, email, and informal FtF meetings.

While individual ICT use can be informative, we also conducted a principal components factor analysis with varimax rotation to see if these ICTs could be both statistically and conceptually grouped. One of the factors met both these criteria and thus we combined the following ICTs into a category we called Public ICTs: Twitter, Vine, Skype, Video chat, Google Hangout, and Instagram. We created a composite measure from these six ICTs and it had an $\alpha=.84, M=1.64$, and $S D=0.97$. The remaining ICTs were treated as distinct predictors. The $M=4.28$, and $S D=2.0$ for the frequency of text messaging between meetings. The $M=5.08$, and $S D=$ 1.81 for the frequency of email use between meetings. The $M=4.85$, and $S D=2.1$ for the frequency of Facebook use between meetings. The $M=4.08$, and $S D$ $=2.13$ for the frequency of FtF conversations between meetings. The $M=2.38$, and $S D=1.95$ for the frequency of using GroupMe.

5.3.3. Attitude toward continuing conversations between meetings. To assess the participants' attitude toward the conversations happening between meetings, we created a six item measure that mirrored an existing behavioral attitude scale [38]. The exact items were measured using the stem, "These conversations in between meetings are:" and they were anchored with never and always. The six items were: helpful; a valuable practice, important for getting things done, a good idea, something positive, and helpful to prepare for the next meeting. A principal components factor analysis with varimax rotation revealed a single factor for this scale and these items created a composite variable with $\alpha=.94, M=5.30$, and $S D=1.30$.

\subsection{Outcome measures}

The two outcomes examined in this study were bonding and bridging social capital. These two scales were identical to the two subscales from Williams (2006) Internet Social Capital Scale [39] except we added the stem, "in this organization" to the survey items. We first used a principal components factor analysis with varimax rotation to confirm the two subscales. Eight of the items - included in William's bonding social capital subscale - loaded on a single factor. Ten of the itemsthe same as Williams' bridging items-loaded on a separate single factor. Bonding social capital had an $\alpha=$ .88 a $M=5.06$, and $S D=1.27$. Bridging social capital had an $\alpha=.92, M=5.47$, and $S D=1.15$.

\section{Results}

The correlations for all variables used in these analyses are displayed in Table 2 . A $p<.05$ acceptance criterion for significance was used for the reported statistical tests. Relevant data assumptions were checked for a regression including multicollinearity, distributions, and outliers. Before conducting the analyses, four univariate and three multivariate outliers were removed.

Table 2. Correlations Between Variables in Models

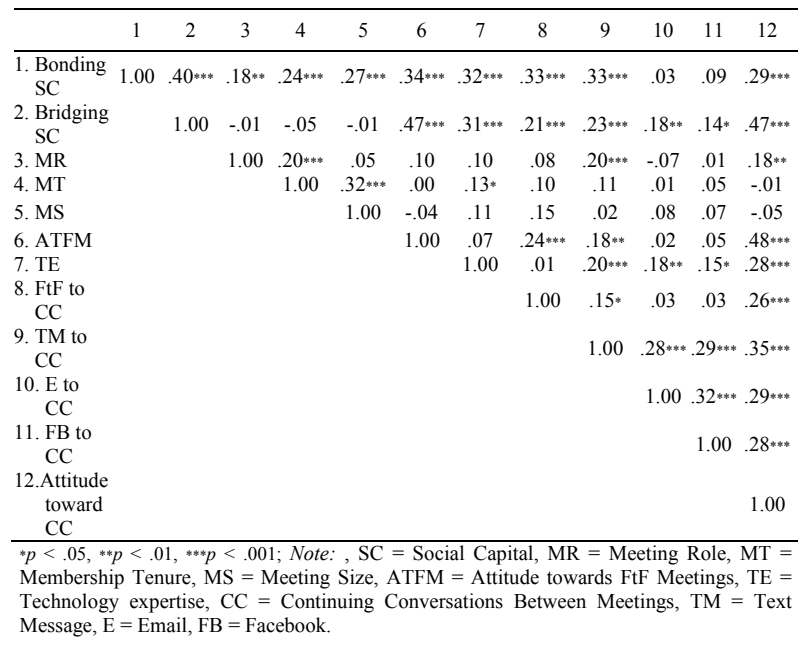

\subsection{Hypothesis 1: Developing bonding social capital during discrete meetings}

Hypothesis one predicted that during FtF meetings, meeting role, membership tenure, meeting size, total organizational membership, perceived overload, and attitude toward the $\mathrm{FtF}$ meeting would increase the development of bonding social capital. We examined this hypothesis using a linear regression and the resulting model was significant with an $F(6,234)=$ $15.22, p<.001$ and an $R^{2}$ adj of .26. Four of the individual predictors were significant: membership tenure $(\beta=.20$, 
$p<.001)$, meeting size $(\beta=.23, p<.001)$, perceived overload, $(\beta=.15, p<.01)$, and positive attitude toward the FtF meeting $(\beta=.34, p<.001)$. See Table 2 .

\subsection{Research question 1: Developing bridging social capital during discrete meetings}

Research question one asked if meeting role, membership tenure, meeting size, total organizational membership, perceived overload, and attitude toward the FtF meeting is related to bridging social capital development. We addressed this research question using a linear regression and the resulting model was significant with an $F(6,233)=16.6, p<.001$ and an $R_{\text {adj }}^{2}$ of .28. Only one of the individual variables was related to bridging social capital and that was having a positive attitude toward the $\mathrm{FtF}$ meeting $(\beta=.53, p<.001)$.

\subsection{Hypothesis 2: Linking ICT use between meetings with social capital}

Hypothesis two predicted that the frequency of using ICTs and FtF conversation between meetings, along with technology expertise and attitude toward continuing conversations between meetings, will contribute significantly to the development of bonding and bridging social capital. We examined hypothesis two using a hierarchical linear regression and there were two blocks of variables entered based on the theoretical model developed in this paper. See Tables 2 and 3 for the complete models.

6.3.1. Bonding social capital. In block one of the regression, meeting role, membership tenure, meeting size, total organizational membership, perceived overload, and attitude toward the FtF meeting were added into the model because they are important FtF meeting variables. Three of these predictors were significant with the individual standardized beta weights being the following: membership tenure $(\beta=.12, p<$ $.05)$, meeting size $(\beta=.21, p<.001)$, and positive attitude toward the FtF meeting $(\beta=.26, p<.001)$. In block two of the regression, we developed the betweenmeeting theoretical model to verify our prediction that it contributed unique variance to bonding social capital. This hypothesis was partially supported (since not all the ICTs used between meetings significantly impacted social capital) and the resulting model was significant with a $F(14,226)=11.97, p<.001$, an $R_{\text {adj }}^{2}$ of .40 , and a significant $\Delta R^{2}=.15 p<.001$. The significant individual predictors included technology expertise $(\beta=$ $.20, p<.001)$, the frequency of $\mathrm{FtF}$ conversations between meetings $(\beta=.19, p<.001)$, and the frequency of text messaging used to continue the conversations between meetings $(\beta=.26, p<.001)$.
6.3.2. Bridging social capital. In block one of the regression, meeting role, membership tenure, meeting size, total organizational membership, perceived overload, and attitude toward the $\mathrm{FtF}$ meeting were added into the model because they are important FtF meeting variables. Two of these predictors were significant with the individual standardized beta weights being the following: meeting role $(\beta=-.16, p<.01)$, and positive attitude toward the $\mathrm{FtF}$ meeting $(\beta=.35, p$ $<.001)$. In block two of the regression, we developed the between-meeting theoretical model to verify our prediction that it contributed unique variance to bridging social capital. This hypothesis was partially supported and the resulting model was significant with a $F(14,225)=11.82, p<.001$, an $R_{\text {adj }}^{2}$ of .39 , and a significant $\Delta R^{2}=.13 p<.01$. The significant individual predictors included technology expertise $(\beta=.17, p<$ $.001)$ and positive attitude toward continuing the conversation between the meetings $(\beta=.29, p<.001)$.

Table 2. Predictors of Bonding Social Capital

Resulting from Conversations Between Meetings

\begin{tabular}{|c|c|c|c|c|}
\hline Predictors & $\beta_{1}$ & $\beta_{2}$ & $R^{2} a d j$ & $\Delta R^{2}$ \\
\hline Block 1: During the FtF Meeting & & & $.26 * * *$ & \\
\hline Meeting role & .06 & -.02 & & \\
\hline Membership tenure & $.20^{* * * *}$ & $.12 *$ & & \\
\hline Meeting size & $.23 * * *$ & $.21^{* * *}$ & & \\
\hline Total organizational membership & .01 & .01 & & \\
\hline Perceived overload & $.15^{* * *}$ & .09 & & \\
\hline Positive attitude toward FtF Meeting & $.34 * * *$ & $.26^{* * *}$ & & \\
\hline Block 2: Continuing Conversations (cc) & & & & $.15^{* * *}$ \\
\hline Technology expertise & & $.20^{* * *}$ & & \\
\hline $\mathrm{FtF}$ conversations $\mathrm{B} / \mathrm{T}$ meetings freq. & & $.19^{* * *}$ & & \\
\hline Text messaging to $\mathrm{cc} \mathrm{B} / \mathrm{T}$ meetings freq. & & $.26^{* * *}$ & & \\
\hline Email to cc $\mathrm{B} / \mathrm{T}$ meetings freq. & & -.10 & & \\
\hline Facebook to $\mathrm{cc} \mathrm{B} / \mathrm{T}$ meetings freq. & & -.06 & & \\
\hline GroupMe to cc B/T meetings freq & & .06 & & \\
\hline Public ICTs cc $\mathrm{B} / \mathrm{T}$ meetings freq. & & -.09 & & \\
\hline Positive attitude toward $\mathrm{cc} \mathrm{B} / \mathrm{T}$ meetings & & -.01 & & \\
\hline Total $R_{a d j}^{2}$ & & & $.40 * * *$ & \\
\hline
\end{tabular}

Table 3. Predictors of Bridging Social Capital Resulting from Conversations Between Meetings

\begin{tabular}{|c|c|c|c|c|}
\hline Predictors & $\beta_{1}$ & $\beta_{2}$ & $R_{a d j}^{2}$ & $\Delta R^{2}$ \\
\hline Block 1: During the FtF Meeting & & & $.28 * * *$ & \\
\hline Meeting role & -.09 & $-.16 * *$ & & \\
\hline Membership tenure & -.03 & -.05 & & \\
\hline Meeting size & .00 & .01 & & \\
\hline Total organizational membership & .05 & .06 & & \\
\hline Perceived overload & .10 & .06 & & \\
\hline Positive attitude toward FtF Meeting & $.53^{* * * *}$ & $.35^{* * * *}$ & & \\
\hline Block 2: Continuing Conversations ( $c c$ ) & & & & $.13 * *$ \\
\hline Technology expertise & & $.17 * *$ & & \\
\hline $\mathrm{FtF}$ conversations $\mathrm{B} / \mathrm{T}$ meetings freq. & & .07 & & \\
\hline Text messaging to $\mathrm{cc} \mathrm{B} / \mathrm{T}$ meetings freq. & & .04 & & \\
\hline Email to $\mathrm{cc} \mathrm{B} / \mathrm{T}$ meetings freq. & & -.02 & & \\
\hline Facebook to cc $\mathrm{B} / \mathrm{T}$ meetings freq. & & -.02 & & \\
\hline GroupMe to $\mathrm{cc} \mathrm{B} / \mathrm{T}$ meetings freq & & .00 & & \\
\hline Public ICTs ce $\mathrm{B} / \mathrm{T}$ meetings freq. & & -.06 & & \\
\hline Positive attitude toward cc $\mathrm{B} / \mathrm{T}$ meetings & & $.29 * * *$ & & \\
\hline Total $R_{a d j}^{2}$ & & & $.39 * * *$ & \\
\hline
\end{tabular}

\subsection{Research question 2: Frequency of specific ICT use between meetings}


Research question two further examined how the 11 specific ICTs, including FtF conversations, used to continue conversations between meetings, related to both forms of social capital development. We examined the results of the hierarchical linear regressions and found that the frequency of text messaging $(\beta=.26, p<$ $.001)$, and the frequency of FtF conversations $(\beta=.19$, $p<.001)$ between meetings were related to higher levels of bonding social capital. The frequency of using ICTs and having FtF conversations were not related to bridging social capital.

\section{Discussion}

This study more fully conceptualizes meetings as a persistent conversation that can build social capital. Our findings suggest that when members of voluntary membership organizations use interpersonal ICTs like text messaging and $\mathrm{FtF}$ conversations to continue meeting conversations, those practices are associated with increased levels of personal bonding social capital. Furthermore, technology expertise and attitudes toward continuing conversations are related to bridging social capital, but the frequency of using specific ICTs is not.

This study contributes to persistent conversation research in three primary ways. First, these findings provide a starting point for the development of a process-based theoretical model that can be used to study meeting practices longitudinally. Second, our findings show that frequent communication between meetings is important when developing bonding social capital. Finally, this research suggests that even in a young, technology-savvy sample, more traditional, FtF communication still matters when the goal is to develop social capital.

\subsection{Theoretical contributions related to persistent conversations}

These findings suggest that our foray into reconceptualizing meetings as a process is feasible and can produce results that inform important outcomes like social capital. Our model acknowledges that during a discrete FtF meeting, people are likely developing social capital, but viewing meetings as persistent conversations through ICT use offers a tangible way to begin studying communicative meeting practices from a process perspective. People do not necessarily appear at a meeting site as a blank slate, conduct the business of the meeting, and leave the meeting site with no ongoing conversations. It is more common that meetings are simply a vehicle to convene-FtF or online - and the work of meetings occurs around discrete meetings.

Our models also extend the sociomaterial understanding of meetings. Continuing meeting conversations through $\mathrm{FtF}$ and ICTs involves combinatorial use of physical and virtual interactions in an ongoing process. This is consistent with the argument that human and material (or technology) agencies - the basic building blocks common to routines and technologies - are inextricably entangled in the process of organizing [12]. Scholars have argued that entwined human and technology agencies create and change routines (e.g., connecting meeting participants through emails or phone calls). Other times, humans and technology combine to produce or alter technologies (e.g., developing add-on applications for a meeting software platform; [12]).

\subsection{Applications of this research}

7.2.1. Bonding social capital findings: Frequent communication. Variables associated with discrete FtF meetings account for over one quarter of the variance in bonding social capital. This makes sense in voluntary membership organizations because people often join these groups to build relationships with others who share their interests [4]. Yet, our findings also suggest that conversations happening between meetings account for a unique $15 \%$ of the variance in bonding social capital. The frequency with which these conversations occur through additional $\mathrm{FtF}$ conversations and text messaging is important to maintain strong relationships. Since attitude toward continuing the conversation is not a significant predictor of bonding social capital, this suggests that relationship-building between meetings is more a process of frequent conversations, occurring through interpersonal channels.

Several other findings deserve explanation because they provide insight into why a process perspective on meetings matters. As predicted, bonding social capital is higher in smaller meetings because there are fewer people and connections are more easily established [40]. Bonding social capital is also higher when people have been members for a longer time. While perceived overload might be present during a discrete FtF meeting or if people attend many meetings [26], our findings suggest that this effect is no longer significant when the conversations are spread out and extended beyond the discrete meeting context. This could be a helpful finding because despite a large body of research on information overload [41], no one has explored how relationshipbuilding information overload occurs or if it occurs at all. These findings suggest that overload could lessen if it is explored using a process perspective.

7.2.2. ICT-related findings. One key contribution this study makes is that we included 11 different ICTs, along with FtF conversation, and linked those to bonding and bridging social capital. Most existing research focuses on one ICT — e.g., Facebook — and uses multiple aspects 
of this ICT to predict social capital development $[31,33]$. While focusing on one specific ICT can provide depth of understanding about that ICT, by including a mix of ICTs, we simultaneously considered that a group of ICTs, can work together as people form relationships.

The frequency that people used $\mathrm{FtF}$ and text messaging between meetings had a strong association with bonding social capital. The $\mathrm{FtF}$ findings are logical because past research has shown that $\mathrm{FtF}$ can offer major advantages that include the development and sustaining of social bonding, sharing experiences in a common space, showing commitment by showing up in person, and being able to manage attention through eye contact [42]. While both of these ICTs can be considered more interpersonal forms of communication, text messaging was more strongly related to bonding social capital than FtF interactions between meetings. This ICT is easily used when people are dispersed, so it makes sense that people keep in touch, continue to build those bonding relationships, and text before they meet FtF again. Furthermore, when using text messaging, people must exchange personal phone number information. In many ways, the social contract required to use this form of communication is entwined with bonding social capital development.

7.2.3. Bridging social capital findings. Bridging social capital, like bonding, is likely developed and reinforced during and between FtF meetings. The two attitudinal measures, having a positive attitude toward $\mathrm{FtF}$ meetings and having a positive attitude toward continuing conversations between meetings, are both strong predictors of bridging social capital.

When considered in the context of FtF meetings, along with attitudes and experiences of between meeting conversations, the frequency with which people use any specific ICTs or FtF conversations between meetings is not a significant predictor for bridging social capital. Yet technology expertise and having a positive attitude toward continuing the conversation do play important roles in bridging social capital. It is possible that bridging social capital development requires more than simple quantity of communication through various ICTs. For weak ties to develop, quality of the communication might be more important than the variables we measured, specifically frequency of continuing conversations. Ellison and colleagues' findings suggest that conversation quality is important in the development of bridging social capital [32].

One of the more surprising findings in this study was that once we included all the variables in our model, using Facebook for conversing between meetings was not associated with either form of social capital. This leads us to consider the context of what we are studying, voluntary membership organizational meetings. In their study, Ellison and colleagues also found no relationship between Facebook use strategies, like initiating contact with new people and maintaining contact with friends and either form of social capital [31]. They found that it was social information seeking behaviors that allowed people to convert latent ties into weak ties and thus influenced social capital development. Perhaps meeting between meetings functions similarly.

\subsection{Limitations and future directions}

This study contributes new ideas concerning the entanglement of meetings and combinatorial ICT use with the development of social capital. While the findings should be helpful as we continue to explore meetings as persistent conversations, there are several limitations. This study used a self-report, crossorganizational sample design, but all the organizations were voluntary membership organizations on a college campus and all the participants were students. This will affect the generalizability of the findings because these students were young adults and these organizations all held FtF meetings on a single campus. We cannot make claims concerning how these findings translate to a work organization.

Another limitation is that we did not include measures for how people use ICTs during meetings. Future studies should include parallel items to further distinguish between different times when ICTs are used for meeting conversations. The sample that was recruited through a mixed-gender recruitment pool was also heavily female. We examined the correlations and there were few bivariate relationships.

Even though our model development and testing conceptualized social capital as outcome variables, it is quite possible that people with high degrees of social capital could approach meeting communication differently. It is plausible that people who have more social capital are more comfortable seeking out interactions between meetings. As we interpret these findings and provide suggestions for future research, this causal direction issue could heighten the relevance of our study and thus, it lends more credence to our argument for treating meetings as processes.

\subsection{Future directions for research}

There are several promising directions for future research that could further explain these findings and build an understanding of how to continue conversations between meetings. First, we should test this process model in a workplace context to see if it is representative and to see if the mix of ICTs used with social capital development differ. Scholars could also use these theoretical models to extend our conceptualization of frequency of use to more descriptive and relationship-quality features of ICTs. 
The first place to extend this research is into ICTs like Facebook and enterprise social media. These studies could build on the large body of current research and extend these past findings to meetings and could incorporate network analysis into the study. Another area to extend this research is to develop and deploy meeting-specific tools, such as collaborative team software (e.g., Loop, Babble; [43]). The evolution of meeting tools designed to integrate the online/offline meeting process could offer unique contributions to this ever-expanding research area. Furthermore, as technologies that allow researchers to monitor actual ICT use advance, they could provide accurate results for the length and frequency of communication between participants and online tools. While the frequency of using tools like Google Hangout, were not significantly related to social capital in the current study, they were also infrequently used. As their popularity grows, their natural integration can provide scholars with interesting new research questions to explore.

\section{Conclusion}

This study not only explains what is happening between FtF meetings, but it also shows how ICTs and $\mathrm{FtF}$ conversations are being used and the resulting increased social capital. This approach to understanding the meeting process is important because it extends concepts of persistent conversations to meetings. Conversations are fluid, ongoing, and they often use multiple ICTs; all concepts ripe for additional study by interdisciplinary scholars.

\section{References}

[1] S.G., Rogelberg, C.S. Scott, and J. Kello, "The Science and Fiction of Meetings", MIT Sloan Management Review, 48, 2007, pp. 18-21.

[2] H.B. Schwartzman, The Meeting: Gatherings in Organizations and Communities, Plenum Press, New York, 1989.

[3] K. Tracy, and A. Dimock, "Meetings: Discursive Sites for Building and Fragmenting Community". In P.J. Kabfleish (Ed.), Communication Yearbook, 28, Lawrence Erlbaum, Mahwah, New Jersey, 2004, pp. 127-136.

[4] T.W.G. Van der Meer, M. Grotenhuis, and P.L.H. Scheepers, "Three Types of Voluntary Association in Comparative Perspective: The Importance of Studying Associational Involvement Through a Typology of Associations in 21 European Countries", Journal of Civil Society, 5, 2009, pp. 227-241.

[5] M.W. Kramer, "A Study of Voluntary Organizational Membership: The Assimilation Process in a Community
Choir", Western Journal of Communication, 75, 2011, pp. 5274.

[6] M.W. Kramer, R.J. Meisenbach, and G.J. Hansen, "Communication, Uncertainty, and Volunteer Membership", Journal of Applied Communication Research, 41, 2013, pp. 18-39.

[7] J.S. Coleman, "Social Capital in the Creation of Human Capital", American Journal of Sociology, 94, 1988, pp. S95S120 (Supplement).

[8] R.D. Putnam, Bowling Alone: The Collapse and Revival of American Community, Simon and Schuster, New York, 2000.

[9] K.K. Stephens, "Multiple Conversations During Organizational Meetings: Development of Multicommunicating Scale", Management Communication Quarterly, 26, 2012, pp. 195-223.

[10] K.K. Stephens, and J.D. Davis, "The Social Influences on Electronic Multitasking in Organizational Meetings", Management Communication Quarterly, 23, 2009, pp. 63-83.

[11] T. Erickson and S. Herring, "Persistent Conversation: A Dialog between Research and Design", in proceedings of the 34th Annual Hawaii International Conference on System Sciences, 2004, pp. 1-3.

[12] P.M. Leonardi, M. Huysman, and C. Steinfield, "Enterprise Social Media: Definition, History, and Prospects for the Study of Social Technologies in Organizations", Journal of Computer-Mediated Communication, 19(1), 2013, pp. 1-19.

[13] S. Herring, "Interactional Coherence in CMC", Journal of Computer-Mediated Communication, 4(4), 2006, pp. 1023.

[14] S.L. Woerner, J. Yates, \& W.J. Orlikowski, "Conversational Coherence in Instant Messaging and Getting Work Done", in Proceedings of the 40th Annual Hawaii International Conf. on System Sciences, 2007, pp. 36-49.

[15] K.M. Chudoba, M.B. Watson-Manheim, K. Crowston, and C.S. Lee, "Participation in ICT-enabled Meetings", Journal of Organizational and End User Computing, 23, 2005, pp. 15-36.

[16] R. Junco, "The Relationship Between Frequency of Facebook Use, Participant in Facebook Activities, and Student Engagement", Computers \& Education, 58, 2012, pp. 162171 .

[17] J.C. Mirivel, and K. Tracy, "Premeeting Talk: An Organizationally Crucial Form of Talk", Research on Language and Social Interaction, 38, 2005, pp. 1-34.

[18] K.K. Stephens, J.O. Sørnes, R.E. Rice, L.D. Browning, and A.S. Sætre, "Discrete, Sequential, and Follow-up Use of 
Information and Communication Technology by Managerial Knowledge Workers", Management Communication Quarterly, 22, 2008, pp. 197-231.

[19] C.W. Scott, L.R. Shanock, and S.G. Rogelberg, "Meetings at Work: Advancing the Theory and Practice of Meetings", Small Group Research, 43, 2012, pp. 127-129.

[20] R. Burt, Structural Holes: The Social Structure of Competition, Harvard, Cambridge, MA, 1992

[21] K.K. Stephens, "The Successive Use of Information and Communication technologies at Work", Communication Theory, 17, 2007, pp. 486-509.

[22] H. Arrow, M.S. Poole, K.B. Henry, S. Wheelan, and R. Moreland, "Time, Change, and Development: The Temporal Perspective on Groups", Small Group Research, 35, 2008, pp. 73-105.

[23] D. Leach, S. Rogelberg, P. Warr, and J. Burnfield, "Perceived Meeting Effectiveness: The Role of Design Characteristics", Journal of Business Psychology, 24, 2009, pp. $65-76$

[24] J.A. Allen, N.L. Willenbrock, and N. Landowski. "Linking Pre-meeting Communication to Meeting Effectiveness", Journal of Managerial Psychology, 29, 2014, pp. 1064-1081.

[25] C.R. Leana, and H.J. Van Buren, "Organizational Social Capital and Employment Practices", Academy of Management Review, 24, 1999, pp. 538-555.

[26] A. Luong, and S.G. Rogelberg, "Meetings and More Meetings: The Relationships Between Meeting Load and the Daily Well-being of Employees", Group Dynamics: Theory, Research, and Practice, 9, 2005, pp. 58-67.

[27] W.R. Scott, Organizations: Rational, Natural, and Open Systems, Prentice-Hall, Englewood Cliffs, NJ, 1981.

[28] J.E. McGrath, "Time, Interaction, and Performance (TIP): A Theory of Groups", Small Group Research, 22, 1991, pp. 147-174.

[29] S.W. Campbell, and N. Kwak, "Mobile Communication and Social Capital: An Analysis of Geographically Differentiated Usage Patterns", New Media \& Society, 12, 2010, pp. 435-451.

[30] Y. Ren et al., "Building Member Attachment in Online Communities: Applying Theories of Group Identity and Interpersonal Bonds", MIS Quarterly, 2012, 36(3), pp. 841864.

[31] N.B. Ellison, C. Steinfield, and C. Lampe, "Connection Strategies: Social Capital Implications of Facebook-enabled Communication Pratices", New Media \& Society, 13, 2011, pp. 873-892.
[32] N.B. Ellison, J. Vitak, R. Gray, and C. Lampe, "Cultivating Social Resources on Social Network Sites: Facebook Relationship Maintenance Behaviors and Their Role in Social Capital Processes", Journal of Computer Mediated Communication, 19(4), 2014, pp. 855-870.

[33] C. Steinfield, J.M. DiMicco, N.B. Ellison, and C. Lampe, "Bowling Online: Social Networking and Social Capital within the Organization", in proceedings of the $4^{\text {th }}$ International Conference on Communities and Technologies, ACM, 2009, pp. 245-254.

[34] F. Stutzman, J. Vitak, N.B. Ellison, R. Gray, and C. Lampe, "Privacy in Interaction: Exploring Disclosure and Social Capital in Facebook", in proceedings of the $6^{\text {th }}$ International AAAI Conference on Weblogs and Social Media, Washington, D.C., 2012.

[35] P.M. Leonardi, “Ambient Awareness and Knowledge Acquisition: Using Social media to Learn Who Knows What and Who Knows Whom", MIS Quarterly, 39, 2015, pp. 747762.

[36] B. Brooks, B. Hogan, N. Ellison, C. Lampe, and J. Vitak, "Assessing Structural Correlates to Social Capital in Facebook Ego Networks", Social Networks, 38, 2014, pp. 1-15.

[37] N.B. Ellison, C. Steinfield, and C. Lampe, "The Benefits of Facebook 'Friend:' Social Capital and College Students' Use of Online Social Network Sites", Journal of ComputerMediated Communication, 12, 2007, pp. 1143-1168.

[38] K.K. Stephens, and S.A. Rains, "Information and Communication Technology Sequences Message Repetition in Interpersonal Interaction", Communication Research, 38, 2011, pp. 101-122.

[39] D. Williams, "On and Off the 'Net: Scales for Social Capital in an Online Era", Journal of Computer-Mediated Communication, 11, 2006, pp. 593-628.

[40] T.W. Smith, "Can We Have Confidence in Confidence? Revisited", In D. F. Johnston. (Ed.) Measurement of Subjective Phenomena, US Bureau of the Census, Washington, DC, 1981, pp. 118-189.

[41] M.J. Eppler, and J. Mengis, "The Concept of Information Overload: A Review of Literature from Organization Science, Accounting, Marketing, MIS, and Related Disciplines", The Information Society, 20, 2004, pp. 325-344.

[42] B.A. Nardi, and S. Whittaker, "The Place of Face-to-face Communication in Distributed Work" in S. Kiesler, and P. Hinds (Eds.), Distributed Work, MIT Press, Cambridge, MA, 2002, pp. 83-111.

[43] T. Erickson and M. Laff, "The Design of the 'Babble' Timeline: A Social Proxy for Visualizing Group Activity over Time", in Proceedings of CHI 2001 of Human Factors in Computing Systems, 2001, pp. 329-341. 